\title{
A Novel ZCS High Step-Up DC-DC Converter for Energy Storage Systems in DC Traction Vehicles
}

\author{
V.V.Subrahmanya Kumar Bhajana ${ }^{1,2}$, Pavel Drabek ${ }^{2}$, Pramod Kumar Aylapogu ${ }^{1}$ \\ ${ }^{1}$ School of Electronics Engineering, KIIT University, Bhubaneswar, India \\ ${ }^{2}$ Regional Innovation Centre for Electrical Engineering, University of West Bohemia, Pilsen, Czech Republic \\ kumarbvvs@yahoo.co.in,kumarbvv@rice.zcu.cz,drabek@ieee.org,aylapogu.pramodkumar@gmail.com
}

\begin{abstract}
This paper proposes a new soft-switched High Step-up DC-DC converter for energy storage systems in DC traction vehicles. In this converter, soft-switching operation, i.e., zero current switching has been obtained by employing dual resonant auxiliary circuits to the conventional step-up DC-DC converter. The auxiliary resonant consists of additional auxiliary switches; inductor and capacitor are used to achieve softcommutation especially when the main active switching devices are being turned-on to turned-off. The main active switching device of this converter achieves soft commutation with reduced voltage stresses and reduced switching losses. Firstly, the operation principles and its design analysis are discussed in detail. Finally, the simulation verification on an input with $100 \mathrm{~V}$ and $350 \mathrm{~V} / 2 \mathrm{~kW}$ converter system operated at $50 \mathrm{kHz}$ switching frequency to validate the theoretical expectations and its effectiveness.
\end{abstract}

Keywords- Zero Current Switching (ZCS); DC-DC; Energy Storage systems; DC traction Vehicles.

\section{INTRODUCTION}

The high-gain, high step-up non-isolated DC-DC converters are being widely used in the applications of energy storage applications (hybrid electric vehicles). In recent years, there are various types of non-isolated step-up converters are implemented; they are operating under hard-switching and soft-switching operations. Firstly, high step-up DC-DC converter [1] based on the integration of three boost converters; this converter switching devices operated under hard-switching condition, achieved the $93 \%$ efficiency at $500 \mathrm{~W}$ output power. The soft-switching operation of the semiconductors in a converter is an alternate way to achieve higher efficiencies, to reduce the voltage/current stresses and improve the overall performance respectively. The soft-switching operation was achieved by adopting the conventional resonant network/auxiliary active resonant network are the sources. A resonant soft-switched step-up converter [2-3] has achieved the zero voltage switching (ZVS) and zero current switching (ZCS) to the semiconductors. However, this converter can be applicable for the lower output voltage and low output power. A parallel resonant based high voltage gain converter [4] has been achieved the zero voltage switching operation to the main semiconductor switching devices at higher switching frequency. However, they achieved low efficiency at low output power. Similarly, researchers focused on a new kind of step-up DC-DC converter [5] employed with a voltage-double-flyback unit to the conventional resonant converter [1] with soft turn-on/turn-off conditions (efficiency $90 \%$ at $100 \mathrm{~W}$ output power). A resonant network based interleaved step-up isolated converter [6] has achieved the ZVS operation. In literature different step-up converters are reported, they are coupled-inductor, switched-capacitor techniques [7] and another converter based on activepassive inductor cells [8] to obtain high-gain and softswitching operation as well.

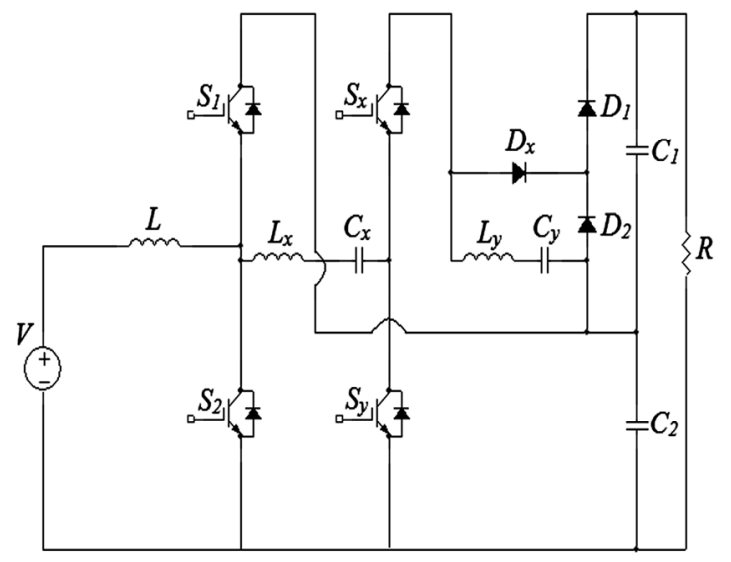

Figure 1. Proposed ZCS High Step-up DC-DC converter

The main attention of this work is to design a new, efficient converter with high gain and high power applications (especially in Battery Back-up systems). This paper mainly proposed a new soft-switching high step-up DC-DC converter for energy storage systems with dual auxiliary resonant circuit. It has major advantages of reduced switching losses, reduced voltage stresses and higher efficiency. The additional advantages of this converter are dual auxiliary active switches operated under soft-turn-on/turn-off conditions. The following section describes the 
proposed converter and its operating principles, Section III deals the design analysis and the simulation results are presented in Section IV.

\section{DESCRIPTION AND OPERATION PRINCIPLE}

Fig.1 shows the proposed new high step-up DC-DC converter. This converter can be operated at high power and to produce high-gain than previously reported resonant topologies [2-3]. The proposed converter semiconductor devices $S_{1}, S_{2}$ are used to regulate the output voltage. By varying the duty cycles of $S_{1}, S_{2}$ are control the output voltage. For $\mathrm{S}_{1}, \mathrm{~S}_{2}$ switches the asymmetrical PWM technique was used to obtain high voltage gain. The PWM signals generated for $S_{x}, S_{y}$ are used to achieve softcommuation of $S_{1}, S_{2}$. The duty cycles of auxiliary switching devices are chosen as $0.1 \%$. The main switching devices $S_{1}, S_{2}$ duty cycles are 0.7 chosen for $S_{1}$ and 0.35 for $S_{2}$. Here, $S_{1}, S_{2}$ are the main switching devices and dual auxiliary resonant circuit switches are $S_{x}, S_{y}$. The resonant inductor $L_{y}$ capacitor $C_{y}$ are resonating, while the $S_{x}$ is being conducted and $D_{x}$ will provide a path to flow of the trapped energy of inductor $L_{y} . S_{x}$ is turned-on before the main switch $S_{1}$ gets turned-off. Similarly, while the $S_{2}$ is commutated, the auxiliary switch $S_{y}$ will be turned-on. However, these dual auxiliary switching devices turned-on for a short time interval. The input inductor current is considered as constant. The equivalent current flow schematics are shown in Fig.3 and the operation of this converter is divided into seven intervals as shown in Fig. 2 with key waveforms described as follows.

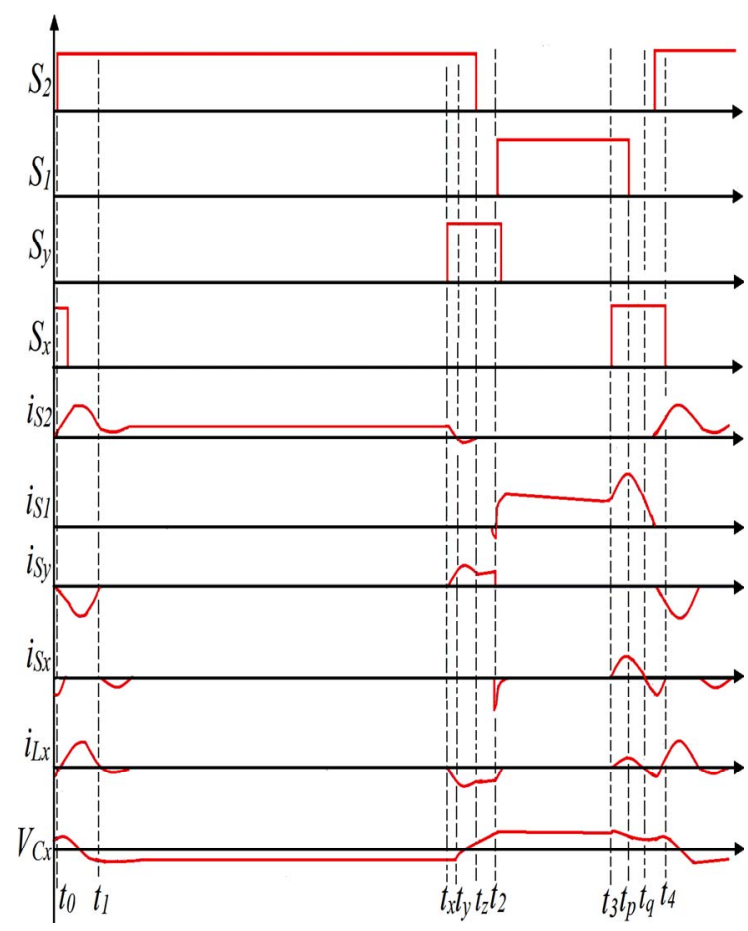

Figure 2. Keywaveforms

Interval $\left(t_{0}-t_{1}\right)$ : Prior to $t_{0}$, the auxiliary switching device $S_{x}$ is already being conducted. At $t_{0}$, the $S_{2}$ is turned-on, then due to the resonant tank ( $L_{x}$ and $\left.C_{x}\right)$, the current flows through it. Current of $S_{2}$ flows linearly and whenever it reached the peak (which is equal to inductor current), the capacitor voltage $C_{x}$ is being discharged to zero and then again starts charging in reverse direction.

$$
\begin{aligned}
& i_{L r}=I_{\text {in }}+\frac{V_{o}}{Z} \sin \omega t \\
& i_{C r}=-\frac{V_{o}}{Z} \sin \omega t \\
& V_{C r}=V_{o} \cos \omega t \\
& \omega=\frac{1}{\sqrt{L_{r} C_{r}}} ; Z=\sqrt{\frac{L_{r}}{C_{r}}}
\end{aligned}
$$

Interval $\left(t_{1}-t_{x}\right)$ : During this stage, the $S_{2}$ is conducting and the energy of the input inductor has been accumulated and capacitor voltage is charged up to the half of the output voltage.

Interval $\left(t_{x}-t_{y}-t_{z}\right)$ : at the beginning of this interval, the auxiliary switching device $S_{y}$ is turned-on under zerocurrent condition, starting a resonance between $L_{x}$ and $C_{x}$. This resonance current forces the IGBT $S_{2}$ current to decrease in a sinusoidal fashion. While the inductor and $S_{2}$ currents reached peak value, the capacitor voltage is discharged to zero. The maximum peak current of the inductor expressed as follows:

$$
\begin{aligned}
& I_{\text {Peak }}=\frac{V_{C r} \text { peak }}{Z} \\
& i_{L r}=I_{\text {in }}-\frac{V_{o}}{Z} \sin \omega t \\
& i_{C r}=\frac{V_{o}}{Z} \sin \omega t \\
& V_{C r}=-V_{o} \cos \omega t
\end{aligned}
$$

To achieve the zero current turn-off for the $S_{2}$, the maximum peak value of the inductor $L_{x}$ should be greater than the input current. During this interval, at $t_{y}$, the ZCS condition is obtained for $S_{2}$ at the instant that current drops to zero and then its anti-parallel diode of $S_{2}$ which provides a path for resonant tank current. End of this interval at $t_{z}$ the anti-parallel diode of $S_{2}$ is turned-off.

Interval $\left(t_{z}-t_{2}\right)$ : Starting of this interval, the antiparallel diode stops conducting and only the auxiliary switching device is in conduction state. At the end of this interval, $S_{y}$ is turned-off and $S_{l}$ is turned-on under zero voltage switching. The resonant inductor current is reached zero and capacitor voltage is charged to the half of the output voltage.

Interval $\left(t_{2}-t_{3}\right): \quad$ At $t_{2}, S_{1}$ is turned-on with ZVS condition. During this interval, the accumulated energy by the inductor $L$ will delivered to the load via $S_{I}$ and output diode $D_{l}$. End of this interval, the auxiliary switch $S_{x}$ is turned-on.

Interval $\left(t_{3}-t_{p}-t_{q}\right)$ : Before the main switch is turned-off, the $S_{x}$ is turned-on at $t_{3}$. The resonant elements start to resonate again. The path of resonant current flows through the $L_{y}, C_{y}$ and the output voltage $V_{o}$. The currents of the $S_{x}, S_{1}$ increases from zero to peak and 
then decreases. At $\mathrm{t}_{\mathrm{q}}$, the $S_{l}$ and $S_{x}$ are turned-off under the ZCS operation.

Interval $\left(t_{q}-t_{4}\right)$ : From the beginning of this interval, the current of the $S_{x}$ becomes negative, and then its antiparallel diode will allow the resonant tank current.
The soft-switching (zero current switching) condition is

$$
Z \leq \frac{V_{o}}{I_{\text {in }}}
$$

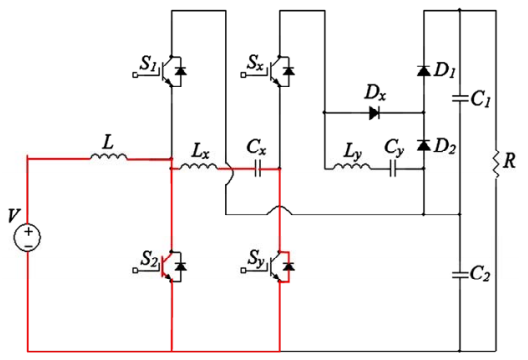

(a) Interval $\left(t_{0}-t_{l}\right)$

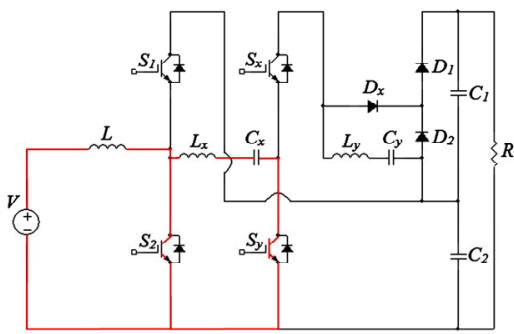

(c) Interval $\left(t_{x}-t_{y}\right)$

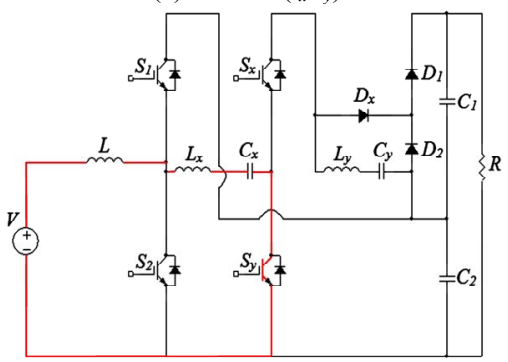

(e) Interval $\left(t_{z}-t_{2}\right)$

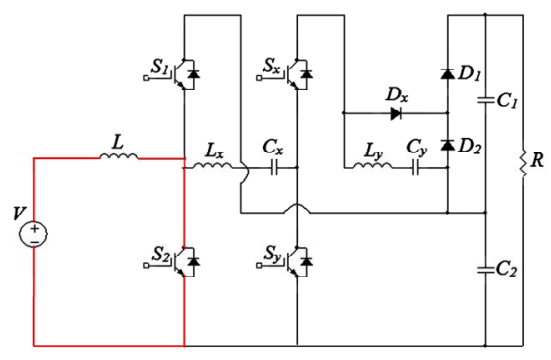

(b) Interval $\left(t_{l}-t_{x}\right)$

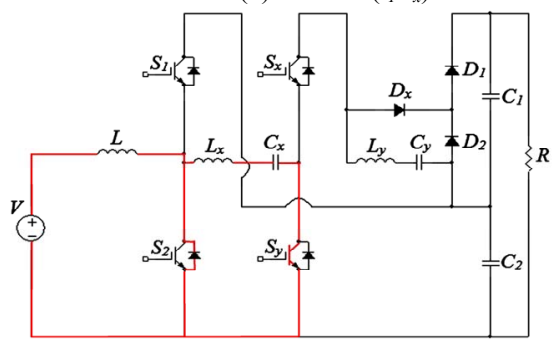

(d) Interval $\left(t_{y}-t_{z}\right)$

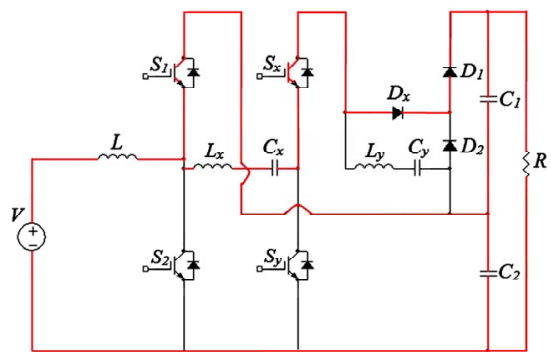

(f) Interval $\left(t_{2}-t_{3}\right)$

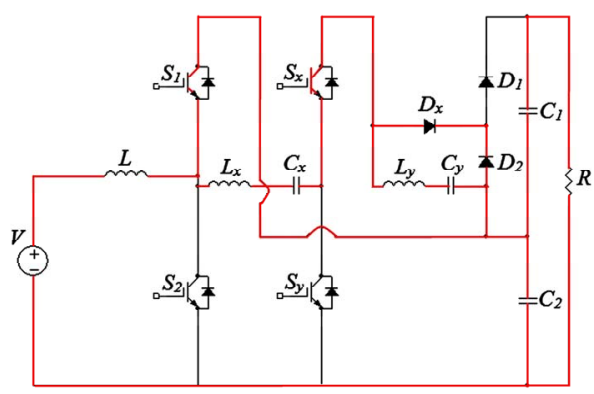

(g) Interval $\left(t_{3}-t_{q}\right)$

Figure 3. Operating modes

\section{DESIGN ANLAYSIS}

The soft-switching condition of the semiconductor devices of proposed converter can be achieved, if the peak input inductor current below the resonant inductor current. The peak current of input inductor L and $L_{x}, L_{y}$ actually depend on the source input current, it can be estimated as follows:

$$
I_{\text {in }}=\frac{2 V_{o} I_{o}}{V_{\text {in }-\max }}
$$

Where $I_{o}=\frac{P_{o}}{V_{o}}$ is the maximum output current.
$\mathrm{Z}$ is the impedance of the resonant circuit

$$
Z \leq \frac{V_{o}}{I_{\text {in }}}
$$

$\mathrm{Z}$ is the impedance of the resonant circuit

$$
f_{r}=\frac{1}{2 \pi \sqrt{L_{n} C_{n}}}
$$

The values of $L_{y}=2 \mu \mathrm{H} ; C_{y}=45 \mathrm{nF}$ chosen to keep the resonant frequency $0.53 \mathrm{MHz}$, which is always above the resonant tank frequency of $L_{x}, C_{x}$. 
The chosen values for $L_{x}=2 \mu \mathrm{H}$ and $C_{x}=85 \mathrm{nF}$ are selected and resonant frequency (10) about $0.38 \mathrm{MHz}$.

Where, $\mathrm{n}=\mathrm{x}$ or $\mathrm{y}$

The impedance of the resonant networks $Z=8.16$ $\Omega(L y, C y)$ and $\mathrm{Z}=4.85 \Omega\left(L_{x}, C_{x}\right)$. The values of impedance of these dual auxiliary resonant networks always less than the output voltage versus maximum input current ratio(8), then the soft-switching condition can be obtained for all switching devices of the converter.

The duty cycle of auxiliary switch is 0.1 which is from $t_{x}-t_{2}$. The total time of $t_{x y}$ obtained from (11) and $t_{\mathrm{yz}}$ are obtained from (12)

$$
\begin{aligned}
& t_{x y \approx 3 p}=\sqrt{L_{x} C_{y}} \sin ^{-1}\left(\frac{Z I_{o}}{V_{i}}\right) \\
& t_{y z \approx p q}=\sqrt{L_{x} C_{y}}\left(\pi-2 \sin ^{-1}\left(\frac{Z I_{O}}{V_{i}}\right)\right)
\end{aligned}
$$

The obtained time of $t_{x y}=0.1 \mu \mathrm{sec}$ and $t_{y z}=0.7 \mu \mathrm{sec}$. The total time of zero current switching of $S_{2}$ is obtained for the values of $L_{x}=2 \mu \mathrm{H}$ and $C_{x}=85 \mathrm{nF}$. Where $t_{\mathrm{yz}}$ is the period of zero current turn-off of $S_{2}$. In this proposed converter the turn-on time of $S_{2}$ is $13 \mu \mathrm{sec}$ and $S_{x}$ turn-on time is $1.6 \mu \mathrm{sec}$ used. Similarly for the switching turn-on times of IGBT $S_{I}=6 \mu \mathrm{sec}$ and $S_{y} 2 \mu \mathrm{sec}$ respectively. The zero current turn-off of the IGBT $S_{l} t_{p q}$ is $1.1 \mu \mathrm{sec}$ and $t_{3 p}$ is $0.1 \mu \mathrm{sec}$.

\section{TABLE I. SIMULATION PARAMETERS}

\begin{tabular}{|l|c|}
\hline \multicolumn{1}{|c|}{ Parameters } & Values \\
\hline Input voltgae(V) & 100 \\
\hline Output voltage & 350 \\
\hline Output Current & $5 \mathrm{~A}$ \\
\hline Switching frequency & $50 \mathrm{kHz}$ \\
\hline Input Inductor(L) & $200 \mu \mathrm{H}$ \\
\hline Resonant Inductor $\left(L_{x} L_{y}\right)$ & $2 \mu \mathrm{H}$ \\
\hline Resonant Capacitor $\left(C_{x}\right)$ & $85 \mathrm{Nf}$ \\
\hline Resonant Capacitor $\left(\mathrm{C}_{\mathrm{y}}\right)$ & $45 \mathrm{Nf}$ \\
\hline
\end{tabular}

\section{SimUlation Results}

The proposed converter model designed for $2 \mathrm{~kW}$ system by using Matlab. The converter specification is aforementioned as in Table I. The simulations were performed for open loop condition. It was confirmed that the simulation results that ZCS turn-off transitions as described above can be achieved for all IGBTs in the converter. The duty cycles chosen for $S_{l}$ is 0.3 and $S_{2}$ is 0.7 . Fig. 4 shows the collector-emitter voltage and current waveforms of the $S_{2}$ and $S_{y}$, which shows that the voltage of the switches are $350 \mathrm{~V}$ and currents are 16A respectively. The soft turn-on operation to the $S_{2}$ and $S_{y}$ was observed. The $S_{2}$ with the ZCS Turn-off and $S_{y}$ turned-off with hard switching operation. Fig.5 represents the $S_{1}, S_{x}$ voltage and current waveforms, it is observed from the obtained results with voltages of the both switches are $350 \mathrm{~V}$ and current of $S_{1}$ is $18 \mathrm{~A}$, $S_{x}$ is nearly 18A.The both switches $S_{I}, S_{x}$ achieved soft turn-on and while they turning-off $S_{1}, S_{x}$ both are turned-off under ZCS condition. So this topology has a reduced switching losses of the main switches, including auxiliary switches Fig.6 show the resonant capacitors $\left(C_{x}, C_{y}\right)$ voltages. Fig.7 represents the auxiliary inductors currents $\left(L_{x}, L_{y}\right)$ waveforms, results obtained are same as theoretical analysis. The obtained results were nearly same as the theoretical analysis.

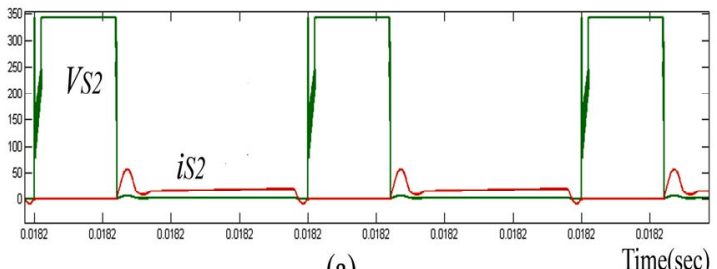

(a)

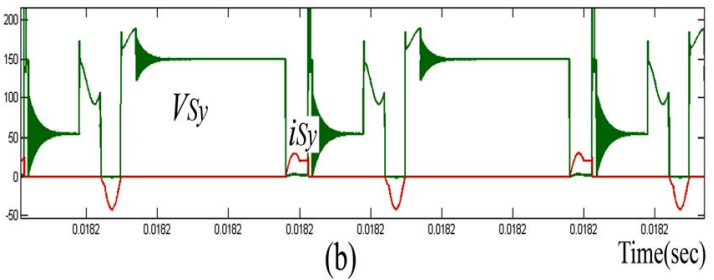

Figure 4. (a) Voltage and Current waveforms of $S_{2}$ (b) Voltage and Current waveforms of $S_{y}$.
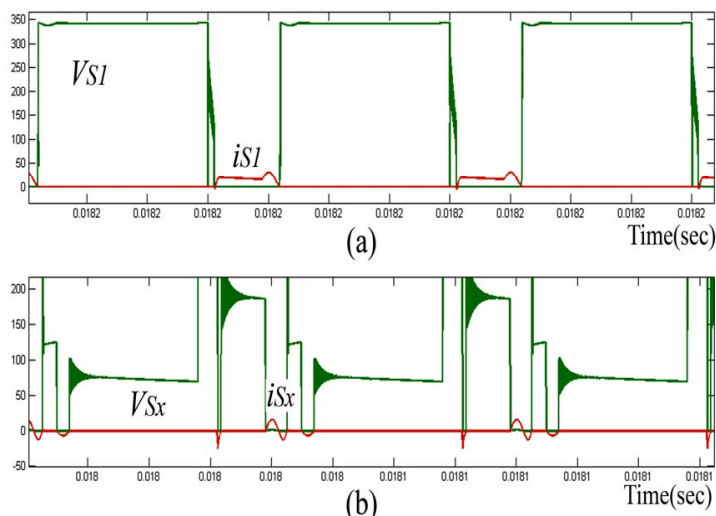

(b)

Figure 5. (a) Voltage and Current waveforms of $S_{l}$ (b) Voltage and Current waveforms of $S_{x}$.
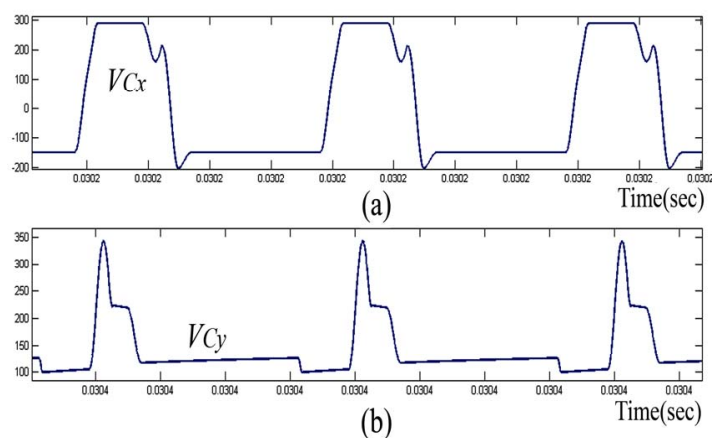

Figure 6. (a) Auxiliary resonant capacitor voltage $V_{C x}$

(b) Auxiliary resonant capacitor voltage $V_{C y}$.

Fig. 8 and Fig.9 ZCS Turn-on Turn-off transitions clearly shows the main switches $\left(S_{1}, S_{2}\right)$ and auxiliary switches $\left(S_{x}, S_{y}\right)$. 


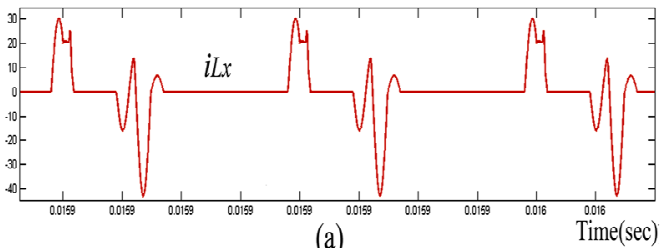

(a)

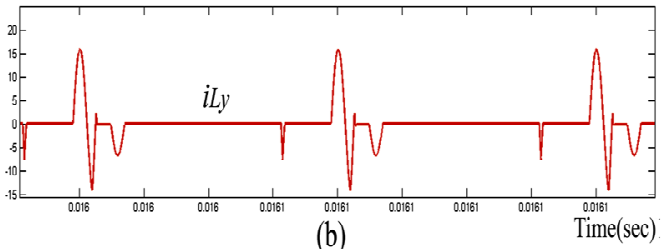

(b)

Figure.7. (a) Auxiliary resonant inductor $L_{x}$ current (b) Auxiliary Resonant inductor $L_{y}$ current.

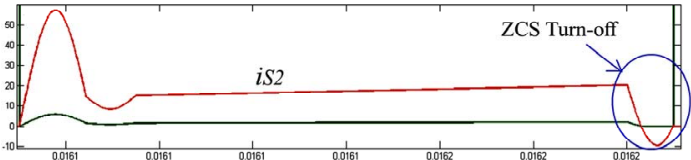

(a)

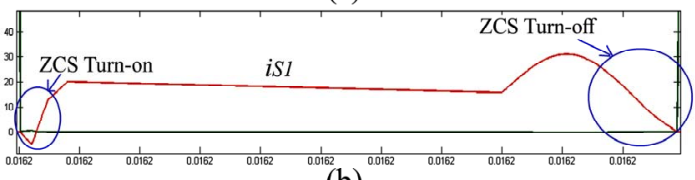

(b)

Figure 8. (a) Turn-on and Turn-off Transition of $S_{2}$ (b) Turn-on and Turn-off Transition of $S_{I}$

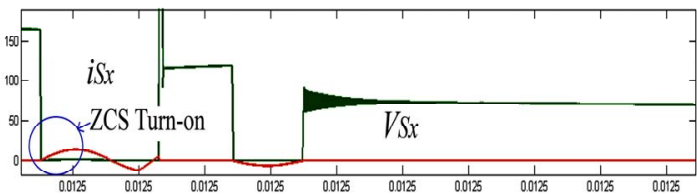

(a)

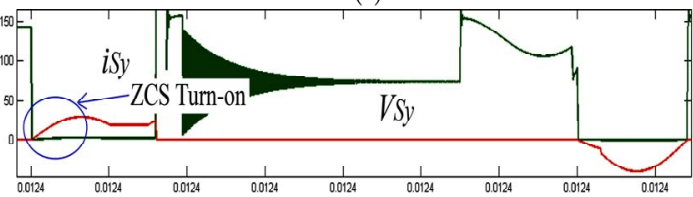

(b)

Figure 9. (a) Turn-on and Turn-off Transition of $S_{x}$

(b) Turn-on and Turn-off Transition of $S_{y}$

\section{CONCLUSION}

This proposed work is a new ZCS high step-up DC-DC converter, which is applicable in battery operated electric vehicles. The operation principles, design and its simulation analysis were presented. The zero current switching turned-off operation was obtained for all the switches in this converter, it is one major advantage, because the auxiliary circuit does not increase additional switching losses and also reduced voltage stresses to the main switches. The simulation results were observed in order to verify the theoretical analysis. This converter can be applicable for highgain and high power applications with improved efficiency over the existing topologies of DC battery back-up systems. The experimental verification of this topology is under progress.

\section{ACKNOWLEDGMENT}

This research has been supported by the Ministry of Education, Youth and Sports of the Czech Republic under the RICE - New Technologies and Concepts for Smart Industrial Systems, Project No. LO1607.

\section{REFERENCES}

[1] R. G. d. A. Cacau, T. B. Lazzarin, M. C. T. Villanueva and I. Barbi, "A high step-up non-isolated DC-DC converter based on the integration of conventional boost converters," IEEE 25th International Symposium on Industrial Electronics (ISIE), Santa Clara, CA, 2016, pp. 408-420.

[2] Y. Park, B. Jung and S. Choi, "Nonisolated ZVZCS Resonant PWM DC-DC Converter for High Step-Up and High-Power Applications," IEEE Transactions on Power Electronics, vol. 27, no. 8, pp. 3568-3575, Aug. 2012.

[3] M. Kwon, S. Oh and S. Choi, "High Gain Soft-Switching Bidirectional DC-DC Converter for Eco-Friendly Vehicles," IEEE Transactions on Power Electronics, vol. 29, no. 4, pp. 1659-1666, April 2014.

[4] D. Patii, A. K. Rathore, D. Srinivasan and S. K. Panda, "High-frequency soft-switching LCC resonant current-fed DC/DC converter with high voltage gain for DC microgrid application," IECON 2014 - 40th Annual Conference of the IEEE Industrial Electronics Society, Dallas, TX, 2014, pp. 4293-4299.

[5] X. Lin, J. Xu, X. Zhou and G. Zhou, "Zero-voltage zerocurrent switching DC/DC converter with high step-up and high efficiency," Electronics Letters, vol. 52, no. 14, pp. 1250-1252, June 2016

[6] F. Shang; G. Niu; M. Krishnamurthy, "Design and Analysis of a High Voltage-Gain Step-up Resonant DC-DC Converter for Transportation Applications," in IEEE Transactions on Transportation Electrification, vol.PP, no.99, pp.1-1, March 2017.

[7] H. M. Maheri; E. Babaei; M. Sabahi; S. H. Hosseini, "High Step-up DC-DC Converter with Minimum Output Voltage Ripple," IEEE Transactions on Industrial Electronics, vol.PP, no.99, pp.1-1, January 2017.

[8] N. Molavi, E. Adib and H. Farzanehfard, "Soft-switched nonisolated high step-up DC-DC converter with reduced voltage stress," IET Power Electronics, vol. 9, no. 8, pp. 1711-1718, June 2016. 